\title{
MODE CROSS-OVER AND DUCTILITY OF DOWELLED LVL AND CLT CONNECTIONS UNDER MONOTONIC AND CYCLIC LOADING
}

\section{Lisa-Mareike Ottenhaus', Minghao Li², Tobias Smith³ ${ }^{3}$ Pierre Quenneville}

1 ABSTRACT: This paper presents an experimental study on dowelled connections in Cross-

2 Laminated Timber (CLT) and Laminated Veneer Lumber (LVL) using $\$ 20 \mathrm{~mm}$ mild steel dowels

3 and internal steel plates. Connections designed to fail in brittle row shear and group tear-out were

4 tested under monotonic loading to assess the validity of analytical models from literature and code

5 provisions. Connections designed to provide non-linearity before failure and thus produce ductility

6 were tested under both monotonic and cyclic loading to study the influence of cyclic loading on

7 ductility and the possibility of mode cross-over. It was found that cross layers in CLT improve

8 ductility. Furthermore, mode cross-over from ductile response to brittle failure was observed in

9 both CLT and LVL connections. Nevertheless, a good amount of ductility was achieved in all

10 layouts (except the LVL connections designed for group tear-out failure) before cross-over to

11 brittle failure occurred.

12 KEYWORDS: Dowelled connections, Cross-laminated timber, Laminated veneer lumber, Ductility,

13 Cyclic loading, mixed-mode failure, mode cross-over

14

${ }^{1}$ Ph.D. Candidate, Department of Civil and Natural Resources Engineering, University of Canterbury, New Zealand, lisa-mareike.ottenhaus@pg.canterbury.ac.nz;

${ }^{2}$ Senior Lecturer, Department of Civil and Natural Resources Engineering, University of Canterbury, New Zealand, minghao.li@canterbury.ac.nz;

${ }^{3}$ Post-doc Research Fellow, Department of Civil and Natural Resources Engineering, University of Canterbury, New Zealand, tobias.smith@canterbury.ac.nz;

${ }^{4}$ Professor, Department of Civil and Environmental Engineering, University of Auckland, New Zealand, p.quenneville@auckland.ac.nz 
16 Traditionally, in timber buildings, connections provide the main source of non-linearity and energy

17 dissipation during a seismic event because timber itself is prone to brittle failure. Therefore,

18 connection behaviour needs to be well understood to ensure seismic safety of timber buildings.

\section{DUCTILITY}

20 A building's ductile capacity is an important seismic design factor. Ductility is a measure of

21 connection non-linearity and is commonly defined as $\mu=\Delta_{u} / \Delta_{y}$, where $\Delta_{y}$ is the yield displacement

22 and $\Delta_{u}$ is the ultimate displacement, often defined as the post-peak displacement at $80 \%$ of the

23 maximum load. Based on the assigned building ductility, the designer needs to detail specific

24 connections with adequate ductility to achieve the desired reduction of seismic demand. This can

25 be a challenging task, as it can be difficult to accurately predict the behaviour of connections under

26 seismic loading. Furthermore, design codes often use ductility obtained from monotonic testing

27 based on the assumption that similar ductile behaviour can be achieved under cyclic loading (Smith

28 et al. 2015, Ottenhaus et al. 2016). In addition, it should be noted that different definitions of the

29 yield point can lead to inconsistencies of ductility evaluations unless clearly defined in design

30 codes (Jorissen and Fragiacomo 2011, Piazza et al. 2011, Flatscher 2016). For the purpose of this

31 paper a connection which has a clearly defined yield point establishing non-linear behaviour is

32 considered to be responding in a ductile manner.

\section{MODE CROSS-OVER}

34 Ductile and brittle behaviour of dowel-type connections have been extensively studied in literature

35 (Jorissen and Fragiacomo 2011, Piazza et al. 2011, Quenneville and Morris 2009, Jensen and

36 Quenneville 2011). Traditionally, ductile and brittle modes are treated as two separate responses.

37 It is assumed that brittle failure can be avoided with adequate fastener spacing allowing the 
connection to develop sufficient ductility. However, fastener embedment and associated timber

39 densification underneath the fastener can reduce the effective shear plane length of the brittle

40 modes and thereby decrease the connection's resistance against brittle failure (Novis et al. 2016,

41 Zhang et al. 2016). A previously ductile responding connection can thus 'cross-over' to brittle

42 failure which is referred to as mixed-mode response.

43 Fig. 1 shows the theoretical concept of cross-over: $F_{B R u}$ refers to the connection's theoretical

44 ultimate brittle resistance. For dowelled connections, $F_{B R u}$ can be the ultimate row shear strength,

$45 F_{R S u}$, the ultimate group tear-out strength, $F_{G T u}$, or the ultimate net tensile strength, $F_{N T u}$. The

46 respective brittle failure modes are displayed in Fig. 2a. As $F_{N T u}$ is not affected by dowel

47 embedment it can be excluded in this illustration. $F_{E Y M u}$ denotes the connection's theoretical

48 ultimate ductile capacity according to the European Yield Model (EYM) as shown Fig. 2b. $F_{E Y M y}$

49 is reached at the displacement $\Delta_{y}$ and is the connection's yield strength, $F_{y}$, regardless of the

50 ultimate failure mode. $F_{u}$ is the obtained ultimate strength at the displacement $\Delta_{u}$. Note that $F_{u}$ is

51 defined as $80 \% F_{\max }$, however, if brittle failure occurs, $F_{u}$ and $F_{\max }$ and the corresponding

52 displacements are identical.

53 Fig. 1 shows the different possible connection responses which are defined by the connection's

54 strength hierarchy:

55 a) Ductile: If $F_{B R u} \gg F_{E Y M u}$, the connection is able to respond in a fully ductile manner as $F_{u}$ $56=F_{E Y M u}$

57 b) Ductile mixed-mode: If $F_{B R u}$ is higher than $F_{E Y M u}$, mode cross-over occurs before $F_{E Y M u}$ is 58 reached: $F_{u}<F_{E Y M u}$. However, the connection may still be able to achieve a high level of 59 ductility depending on the initial difference between $F_{u}$ and $F_{E Y M y}$ and accordingly the 60 difference between $\Delta_{u}$ and $\Delta_{y}$. 
c) Nominally ductile mixed-mode: If the strength hierarchy of the connection is $F_{E Y M y}<F_{B R u}$ $<F_{E Y M u}$, only a small amount of non-linear deformation can be achieved before mode crossover occurs resulting in a connection with nominal ductility.

d) Brittle: If $F_{B R u}<F_{E Y M y}<F_{E Y M u}$, the connection will fail without any fastener yielding.

66 If the connection's ductile behaviour is well described and the expression for the reduced brittle

67 strength, $F_{B R r e d}$, is known, it is possible to accurately predict $\Delta_{u}$ and the connection's ductility

$68 \mu=\Delta_{u} / \Delta_{y}$ (Zhang et al. 2016, Novis et al. 2016), without conducting experimental testing.

70 The effect of cyclic loading on strength and ductility has been studied in literature (Mohammad et

71 al. 1998, Yasumura 1998). As fastener embedment can only provide limited hysteretic energy

72 release under cyclic loading, timber structures rely on fastener yielding for ductility during seismic

73 events. However, this ductile response can be impaired by onset of brittle failure due to mode

74 cross-over.

\section{EXPERIMENTS}

77 Monotonic and cyclic tensile tests were performed on dowelled connections in Laminated Veneer

78 Lumber (LVL) and Cross-Laminated Timber (CLT) made out of New Zealand Radiata pine. The

79 connection layouts, based on Eurocode 5 provisions (EN 1995-1-1 2004) and models developed

80 by Quenneville and Morris (2009), were designed to result in ductile and brittle responses with

81 little margin between the different failure modes. Subsequently, the accuracy of the strength

82 prediction and the mode cross-over was assessed. One connection layout was additionally 
83 subjected to cyclic loading according to ISO 16670 (2003) to study the effects of cyclic loading

84 on strength, ductility and mode cross-over.

\section{TEST SET-UP AND MATERIALS}

87 As shown in Fig. 3a, all CLT and LVL connection specimens were $610 \mathrm{~mm}$ long and $240 \mathrm{~mm}$ 88 wide with a $20 \mathrm{~mm}$ slot to insert a $20 \mathrm{~mm}$ thick Grade 300 steel plate. The LVL specimens were

$89133 \mathrm{~mm}$ thick with a side member thickness of $t_{l}=56.5 \mathrm{~mm}$. The CLT specimens were $130 \mathrm{~mm}$

90 thick with a side member thickness of $t_{l}=55 \mathrm{~mm}$. The outer layers were $35 \mathrm{~mm}$ thick, whereas the

91 cross-layers and inner layer were $20 \mathrm{~mm}$ thick.

92 The LVL specimens were grade LVL13 with a manufacturer specified Modulus of Elasticity 93 (MOE) value of $13.2 \mathrm{GPa}$ and a measured average moisture content of $8.4 \%$. The veneers in the

94 LVL specimens were $2.5-4.4 \mathrm{~mm}$ thick and glued with phenolic adhesive complying with 95 AS/NZS 4357.0 (2005). The mean and characteristic ( $5^{\text {th }}$-percentile) densities were $\rho_{\text {mean }}$ $96=591 \mathrm{~kg} / \mathrm{m}^{3}$ and $\rho_{k}=585 \mathrm{~kg} / \mathrm{m}^{3}$, respectively.

97 The CLT connection specimens had an average moisture content of 9.9\%. Timber lamellas in the

98 CLT specimens were $120 \mathrm{~mm}$ wide and glued with single-component polyurethane adhesive 99 (PUR) without edge-gluing. The average MOE of the lamellas was $8 \mathrm{GPa}$ in the outer layers and $1006 \mathrm{GPa}$ in the inner layers. The mean and characteristic density were $\rho_{\text {mean }}=443 \mathrm{~kg} / \mathrm{m}^{3}$ and $\rho_{k}=$ $101412 \mathrm{~kg} / \mathrm{m}^{3}$, respectively.

102 As shown in Fig. 3b, the top connection joining to the loading head was designed to be 103 significantly stronger than the bottom connection subjected to destructive testing and consisted of 104 six $\$ 25 \mathrm{~mm}$ Grade 300 dowels reinforced with self-tapping screws. The bottom connection 105 consisted of four chamfered $\phi 20 \mathrm{~mm}$ dowels that were flush with the timber surface and were 
sourced from the same batch as those tested in dowel bending and embedment. The connection

107 was designed as described in the following section with different layouts targeting three different

108 strength hierarchies in LVL, depending on the fasteners spacing $a_{1}$ and $a_{2}$, and the end distance $a_{3}$

109 and the edge distance $a_{4}$ as shown in Fig. 3c and Table 1:

$110 \quad$ - brittle row shear failure (RS) under monotonic loading $F_{E Y M y}<F_{R S u}<F_{E Y M u}$

111 - brittle group tear out failure (GT) under monotonic loading $F_{G T u}<F_{E Y M y}<F_{E Y M u}$

112 - ductile response under monotonic (DT-M) and cyclic (DT-C) loading $F_{E Y M y}<F_{E Y M u}<F_{B R u}$

113 The same layouts were adopted for the CLT specimens to study the reinforcing effect of the cross

114 layers depending on the connection layout. It should be noted that the designations RS, GT, DT

115 refer to the connection layout rather than the observed actual response from experimental testing.

116 Five connection replicates for each layout were tested with a loading rate of $1 \mathrm{~mm} / \mathrm{s}$ under

117 monotonic loading and $10 \mathrm{~mm} / \mathrm{s}$ under cyclic loading. The cyclic tests followed the ISO loading

118 protocol (ISO 16670 2003), with the specimens being loaded to the target displacement of each

119 cycle group and then returned to zero displacement. Each cycle group consisted of three repeated

120 cycles whose target displacement was a certain percentage of the average $\Delta_{u}$ obtained from the

121 monotonic tests. This was to represent a typical hold-down connection subjected to repeated

122 uplifting in a seismic event. Displacements were measured with potentiometers at six different

123 locations (front, back, two locations on each side) and averaged.

124

125 STRENGTH PREDICTION

126 Table 2 lists the characteristic strength properties of CLT, LVL, and the fasteners that served to 127 calculate the connection's nominal strength, taken as the $5^{\text {th }}$-percentile value of the strength 128 distribution. All strength predictions were based on measured material properties rather than 
129 supplier specified properties with the exception of the characteristic shear strength, $f_{v, k}$, and

130 characteristic tensile strength, $f_{t, k}$, which were provided by the CLT and LVL manufacturers.

131 As embedment strength values for CLT were not available, additional CLT embedment tests were

132 performed according to AS/NZS ISO 10984.2 (2015) and the characteristic embedment yield

133 strength, $f_{h, y, k}$, was determined from the load-deformation graphs according to EN 12512 (2013).

134 The relationship $f_{h, y, k} \approx 0.8 f_{h, u, k}$ was established with $f_{h, u, k}$ being the characteristic ultimate 135 embedment strength (Ottenhaus et al. 2017). The characteristic embedment strength for the LVL 136 specimens was calculated according to Franke and Quenneville (2011) as $137 f_{h, u, k}=0.075(1-0.0037 d) \rho_{k}$. Furthermore, three-point dowel bending tests were performed 138 according to AS/NZS ISO 10984.1 (2015) and the plastic yield moment was determined as $139 M_{y, p}=428,700 \mathrm{Nmm}$ from which the elastic yield moment was calculated as $M_{e, p}=(6 \pi / 32) M_{y, p}$ 140 (Ottenhaus et al. 2017).

142 The ductile strength prediction was based on the European Yield Model (EYM) as presented in 143 Eurocode 5 (EN 1995-1-1 2004). An attempt was made not only to predict the connection's 144 characteristic maximum capacity $F_{\max , k}$ (equivalent to $F_{v, R k}$, in Eurocode 5), but also to predict the 145 characteristic yield strength, $F_{y, k}$. The governing ductile mode was EYM VI (see Fig 2b). The 146 corresponding ductile capacity was calculated using Equations (1) and (2), simply referred to as $147 \quad F_{E Y M y}$ and $F_{E Y M u}$ in the following context.

149 The brittle strength prediction for LVL was adopted from Quenneville and Morris (2009) and 150 conservatively modified for accuracy, as shown in Equation (3) and (4). The calibration factors $\alpha_{\mathrm{i}}$ 151 were adopted from Quenneville and Morris (2009). Currently, no expressions for the reduced 
152 brittle strength due to dowel embedment, $R S_{\text {red }}$ and $G T_{\text {red }}$, exist (Zhang et al. 2016). Therefore, it

153 was unlikely to accurately represent the impact of this phenomenon on the brittle failure prediction.

$$
\begin{aligned}
& F_{E Y M_{y, k}}=4 \times 2 f_{h, y, k_{t}} t_{1} d\left(\sqrt{2+\frac{4 M_{y, e, k}}{f_{h, e, k} d t_{1}^{2}}}-1\right) \\
& F_{E Y M_{u, k}}=4 \times 2 f_{h, u, k_{t}} t_{1} d\left(\sqrt{2+\frac{4 M_{y, p, k}}{f_{h, u, k} d t_{1}^{2}}}-1\right) \\
& F_{R S_{u, k}}=2 n_{2} \times \alpha_{1} f_{v, k} k_{L S}\left(n_{1} \min \left[a_{1} ; a_{3}\right]-d\right) 2 t_{1} \\
& F_{G T_{u, k}}=2 \times \alpha_{1} f_{v, k} k_{L S}\left(n_{1} \min \left[a_{1} ; a_{3}\right]-d\right) 2 t_{1} \\
& +\alpha_{2} f_{t, k}\left(n_{2}-1\right)\left(a_{2}-d\right) 2 t_{1}
\end{aligned}
$$

154 where $k_{L S}=$ loading surface factor $\left(0.65\right.$ for internal steel plate), $\alpha_{1}=$ row shear calibration factor

155 (0.84), $\alpha_{2}=$ group tear-out calibration factor (1.26), $a_{i}=$ fastener spacing (shown in Fig. 3c), $d=$ 156 fastener diameter, $t_{1}=$ single side timber thickness.

157 Table 3 gives the predicted connection strength values based on Equation (1) through Equation (4).

158 Currently, there are no brittle strength predictions available for the CLT connections due to the 159 crosswise layup of lamellas. However, the aim was to study the reinforcing effect of the cross160 layers depending on different connection layouts. Therefore, the CLT specimen layouts were based 161 on the LVL and the designations RS and GT were adopted for consistency.

\section{EXPERIMENTAL RESULTS OF CLT CONNECTIONS}

164 The CLT connections had 3-stages of response before failure:

165 1) Onset of dowel bending and yielding (Fig. 4a); 
2) Continued yielding, out-of-plane bending of the timber members and onset of crack growth in cross layers (Fig. 4b). Shear failure in cross layer and separation of outer layer and cross layer close to the glue line;

169 3) Final brittle rupture in the outer layers (Fig. 4c and d).

170 Development of the second stage was influenced by the position of lamella edges in the outer 171 layers and inherent imperfections such as knots and initial cracks. Furthermore, out-of-plane 172 bending of the timber members and separation of the cross layer from the outer layer often caused

173 premature brittle failure (Fig. 4e). The yield strength, $F_{y}$, of the load-displacement curves was 174 defined according to EN 12512 (2013) with correction of some initial slip. This method was 175 deemed appropriate as it does not produce a yield point for brittle behaviour (Brühl et al. 2011). 
177 Table Tables 4 and 5 display the yield strength, $F_{y}$, maximum strength, $F_{\max }$, strength at failure,

$178 F_{u}$, initial stiffness, $K$, and the corresponding displacements $\Delta_{y}, \Delta_{F m a x}$, and $\Delta_{u}$. The ductility was

179 calculated as $\mu=\Delta_{u} / \Delta_{y}$ and the failure mode as well as the ductility classification were adopted

180 from Smith et al. (2006): $\mu \leq 4$ brittle/low ductility (B), $4<\mu \leq 6$ mixed (M), $\mu>6$ ductile (D).

181 The load-displacement curves and the strength predictions are shown in Fig. 5 and Fig. 6.

182 The load-displacement hysteretic curves for the DT-C specimens are shown in Fig. 7. It should be

183 noted that RS01 and RS04 displayed high ductility as $\Delta_{y}$ was very small compared to $\Delta_{F m a x}$ and

$184 \Delta_{u}$. This would not be the case if another method such as Energy Equivalent Elastic Plastic (EEEP)

185 method was used to establish $\Delta_{y}$ (Jorissen and Fragiacomo 2011, Brühl et al. 2011, Piazza et al.

186 2011). Another option to quantify ductility in a more meaningful manner is to use a combination

187 of relative and absolute ductility definitions that can potentially also avoid the determination of

188 the yield point as suggested by Flatscher (2016).

\section{EXPERIMENTAL RESULTS OF LVL CONNECTIONS}

191 For the LVL connection specimens, all DT-M, DT-C and RS specimens ultimately failed in row

192 shear or tensile splitting with significant dowel yielding in bending. The GT specimens developed

193 the expected group tear-out with little dowel bending (Fig. 8).

194 Tables 6 and 7 list the yield strength, $F_{y}$, peak strength, $F_{\max }$, ultimate strength, $F_{u}$, initial stiffness,

$195 K$, and the corresponding displacements $\Delta_{y}, \Delta_{F m a x}, \Delta_{u}$. The yield point, failure mode and ductility

196 were established with the same methods as for the CLT connections. The load displacement curves

197 and strength predictions are displayed in Fig. 9 and 10. The hysteretic curves for the DT-C

198 specimens are shown in Fig. 11. 
201 The test results showed that the CLT and LVL connections with $\phi 20 \mathrm{~mm}$ dowels can be designed

202 to achieve good ductility (on average $6.2-14.6$ from the ductile responses) and ultimate

203 displacement capacity even if the connection is eventually governed by the mixed-mode response,

204 as shown in Table 8. It should be emphasized that the achieved connection ductility does not equate

205 system ductility or overall building ductility which requires the consideration of total building

206 displacement (Moroder et al. 2014).

207

\section{DUCTILITY IN CLT CONNECTIONS}

209 Non-glued edges and gaps in the crosswise CLT layup affected the strength and resulted in high

210 scatter of the test results. Therefore, it could be beneficial to spread out fasteners over a wider

211 connection area to engage more cross layers and prevent brittle failure. Low rolling shear strength

212 of the cross layers can cause separation from the outer layers and lead to brittle failure as the

213 smooth steel dowels are not able to prevent opening up of the side members. Further investigations

214 should also examine the influence of fastener spacing, edge distances and location of lamella gaps

215 on ductility and brittle failure modes through comprehensive experimental research and/or robust

216 finite element modelling.

217 For the CLT connections, the RS layout achieved twice as much ductility at the DT layout, which

218 indicated that the increase of the end distance $a_{3}$ from $5 d$ to $7 d$ was very beneficial. 
221 The LVL connections can achieve very high ductility if edge distances are increased such that

$222 F_{B R r e d}>F_{E Y M u}$. However, this still requires quantification of the strength reduction, $F_{B R k, \text { red }}$, due to 223 dowel embedment (Zhang et al. 2016).

224 The DT-M, DT-C layout and the RS layout achieved good ductility (average range of 6.2 - 9.8), 225 whereas the GT layout failed before the onset of significant non-linear behaviour (average ductility 226 of 2.5). The increase of edge distance $a_{3}$ from DT to RS improved the ductility in the LVL 227 connections, although the effective shear plane length was reduced from $2 \cdot \min \left[a_{1}, a_{3}\right]-d=$ $2282 \cdot 100-20=180 \mathrm{~mm}$ to $2 \cdot 80-20=140 \mathrm{~mm}$.

229 If it is assumed that the initial stiffness, $K$, is independent of the connection layout, the yield 230 displacement, $\Delta_{y}$, should be identical for all connection layouts as the EYM strength is independent 231 of the connection layout $\left(\Delta_{y}=F_{E Y M y} / K\right)$. As shown in Fig. 1, the DT layout should theoretically 232 achieve a higher ultimate displacement, $\Delta_{u}$, than the RS layout before mixed-mode failure occurs. 233 Consequently, the DT layout's ductility, $\mu_{D T}$, should be higher than the RS ductility, $\mu_{R S}$, and the 234 following expression should hold: $\mu_{D T} \geq \mu_{R S}$.

235 However, for the LVL specimens, the observed ultimate displacements were $\Delta_{u, D T}=7.4 \mathrm{~mm}$ and $236 \Delta_{u, R S}=8.3 \mathrm{~mm}$, and the values for initial stiffness were $K_{D T}=144 \mathrm{kN} / \mathrm{mm}$ and $K_{R S}=157 \mathrm{kN} / \mathrm{mm}$, 237 which resulted in $\mu_{R S}>\mu_{D T}$. This finding suggests that the increased edge distances and fastener 238 spacing might have an impact on the initial stiffness, $K$, and brittle strength reduction, $F_{B R, \text { red }}$. This 239 issue should be further investigated. 
242 The CLT and LVL connection specimens showed increased ductility under cyclic loading: cyclic 243 ductility was 1.15 times larger than monotonic ductility for the CLT connections, and 1.58 times

244 larger for the LVL connections. This finding is in agreement with previous observations by 245 Mohammad et al. (1998) but contradicts findings by Yasumura (1998). Therefore, the difference 246 between cyclic and monotonic ductility should be further investigated with a larger sample size 247 taking different displacement rates and loading protocols into account.

\section{MODE CROSS-OVER}

250 Table 8 compares the respective strength predictions $\left(F_{E Y M y, k}, F_{E Y M u, k}, F_{B R u, k}\right)$ to the experimentally 251 obtained average maximum values.

252 Mixed-mode response was observed in the DT layouts and brittle failure occurred before the 253 ultimate ductile capacity, $F_{E Y M u}$, was reached: $F_{E Y M y}<F_{u}=F_{B R r e d}<F_{E Y M u}<F_{B R u}$.

254 The strength predictions of the brittle layouts (GT and RS) in the LVL connections were 255 conservative. Such conservatism is deemed appropriate due to the inherently high scatter in 256 strength of brittle modes. However, too much conservatism should be avoided as it results in 257 uneconomic designs.

258 It should be noted that the determination of $F_{y}$ according to EN 12512 (2013) depends on the 259 measured ultimate strength, $F_{u}$. Nevertheless, the prediction of $F_{y}$ was fairly accurate for all the 260 connection designs with the average error being within 10\%. However, the error may be larger if 261 all the supplier specified material properties were used for the strength predictions.

262 Ultimate and yield strength values achieved under cyclic loading were slightly higher than those 263 under monotonic loading. As crack growth is dependent on time, this strength increase may be due 
264 to the higher displacement rate under cyclic loading. However, this hypothesis should be verified

265 further with a larger sample size for different displacement rates and loading protocols.

267 CONCLUSIONS

268 A total of 40 experimental tests were performed on dowelled CLT and LVL connections with three 269 different layouts (ductile, row shear and group tear-out). Embedment tests on CLT and dowel

270 bending tests were also performed to calibrate the input parameters for strength predictions of the 271 connections.

272 The experimental results showed that the models for brittle failure (Quenneville and Morris 2009)

273 were able to conservatively predict row shear failure and group tear-out failure in the LVL 274 connection layouts. Given the high scatter in brittle modes, conservatism for brittle connection 275 failure is deemed appropriate. However, better calibration of the model parameters could be 276 performed to reduce some of this conservatism.

277 Purely ductile response $\left(F_{u}=F_{E Y M u}\right)$ was not achieved in the monotonic or cyclic experiments of 278 the LVL connections as dowel yielding through bending was followed by row shear. This was due 279 to the fact that the connection capacity decreases as the effective shear plane length is reduced by 280 dowel embedment and timber densification underneath the dowel (Zhang et al. 2016, Novis et al. 281 2016). This mixed-mode response could not be reasonably predicted due to the lack of good 282 prediction of the brittle strength reduction, $F_{B R r e d}$.

283 Brittle failure modes need to be further studied for dowelled CLT connections. Existing gaps in 284 non-edge glued CLT can act as pre-existing shear failure planes which dramatically decrease 285 connection strength and ductility. Low rolling shear strength of the cross layers may also lead to 286 pre-mature failure which causes further strength reduction. However, if bolts were used as 
287 fasteners, they could help prevent the out-of-plane bending and opening up of the side members

288 in the connection. Nevertheless, there was an indication that the cross layers had a reinforcing

289 effect for the CLT connections and good ductility (average ductility $7.3-14.6$ ) was achieved if

290 brittle failure was avoided.

291 Slightly higher yield and ultimate strength and slightly greater ductility were achieved under cyclic

292 loading when compared to monotonic loading for both CLT and LVL connections (average of 8.4

293 vs 7.3 for the CLT connections and 9.8 vs 9.1 for the LVL connections). This indicates that it is

294 possible to represent the cyclic backbone curves by the monotonic curves in terms of strength and

295 ductility for dowelled connections that respond in a ductile mixed-mode manner. However, further

296 experimental testing with a larger sample size, different connection layouts, displacement rates,

297 and loading protocols is required to confirm this finding. Furthermore, a test series with purely

298 ductile response is required to extrapolate this finding to completely ductile connection layouts.

299 The test results suggest that good ductility (on average 7.3 - 14.6) can be achieved for dowelled

300 connections in LVL and CLT even if mixed-mode response is ultimately governing, as long as the

301 connection layout is configured such that the ultimate ductile strength based on the European Yield

302 Model is lower than the ultimate brittle strength $F_{E Y M u} \leq F_{B R u}$. Further increase in connection

303 ductile capacity could be achieved if the strength hierarchy for purely ductile response is targeted:

$304 \quad F_{E Y M u} \leq F_{B R u, r e d}$.

305 In this study, EN 12512 was used to define the yield point as it does not produce a yield point for

306 brittle failure. However, when the initial stiffness is calculated between $10 \%$ and $40 \%$ of the

307 maximum load, the established yield displacement, $\Delta_{y}$, can be very small which can lead to a

308 misleadingly high ductility $\mu$ in some cases. Critical evaluation of the yield point and ductility

309 definitions is required to give more rational ductility estimations. 


\section{ACKNOWLEDGEMENTS}

312 The authors would like to acknowledge Natural Hazard Research Platform of New Zealand and

313 Department of Civil \& Natural Resources Engineering at University of Canterbury for providing

314 research funding. XLAM NZ Ltd. and Nelson Pine Idustries Ltd. are also gratefully acknowledged

315 for providing the test specimens. The authors would also like to thank Mr. Shane Magic and Mr.

316 Jared McPherson for conducting the CLT embedment tests and Mr. Alan Poynter for providing

317 technical laboratory assistance. 


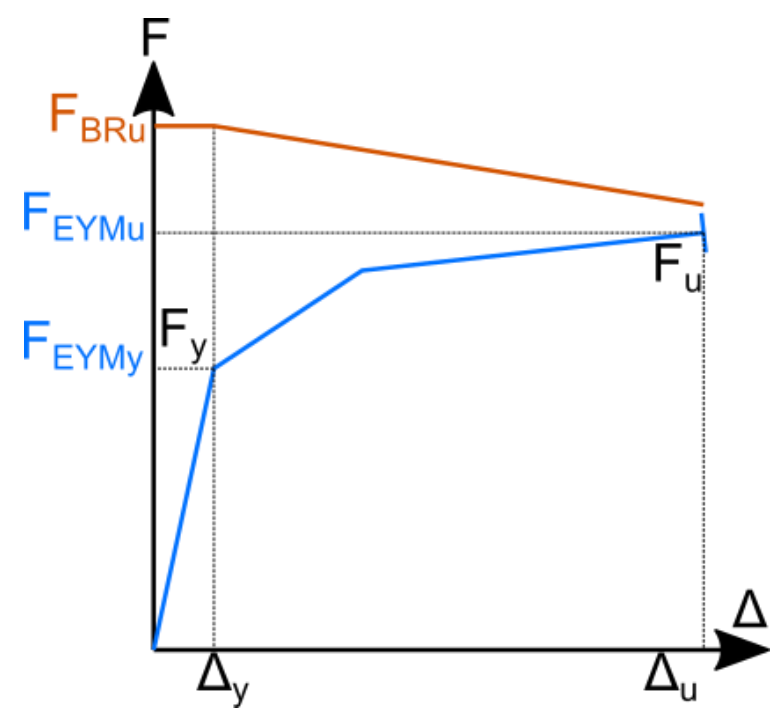

(a)

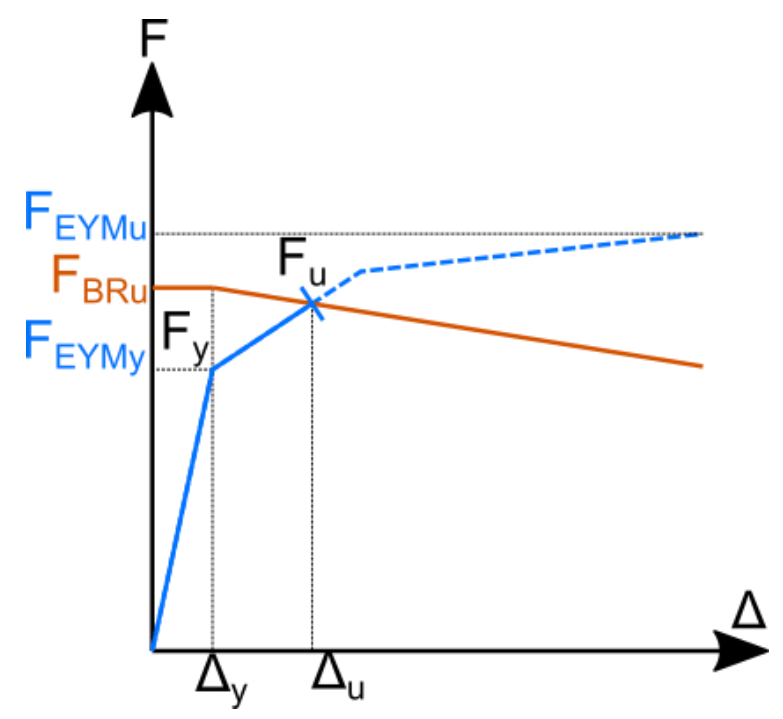

(c)

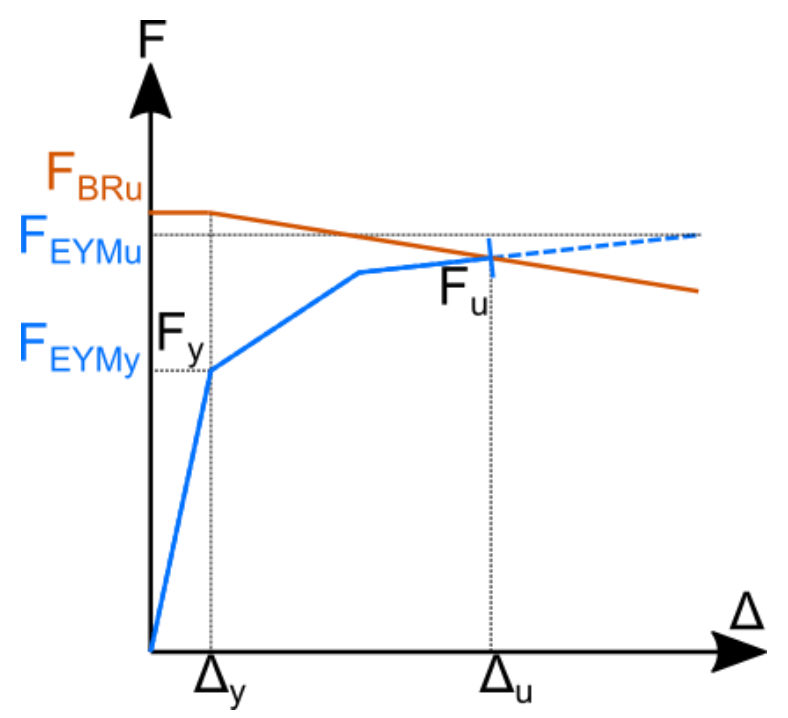

(b)

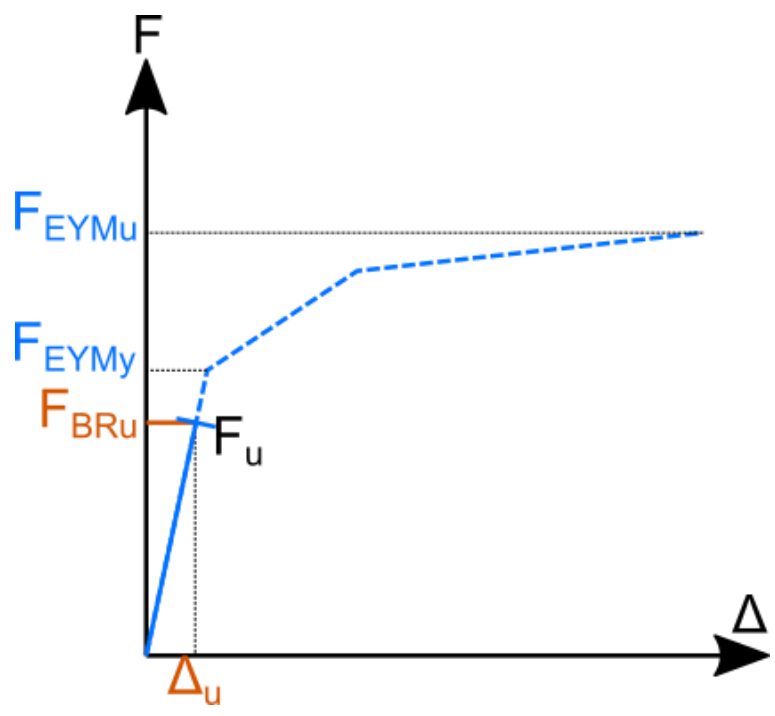

(d)

320 Fig. 1. Concept of mode cross-over from left to right: (a) Ductile, (b) ductile mixed-mode, (c) low 321 ductility mixed-mode, (d) brittle 

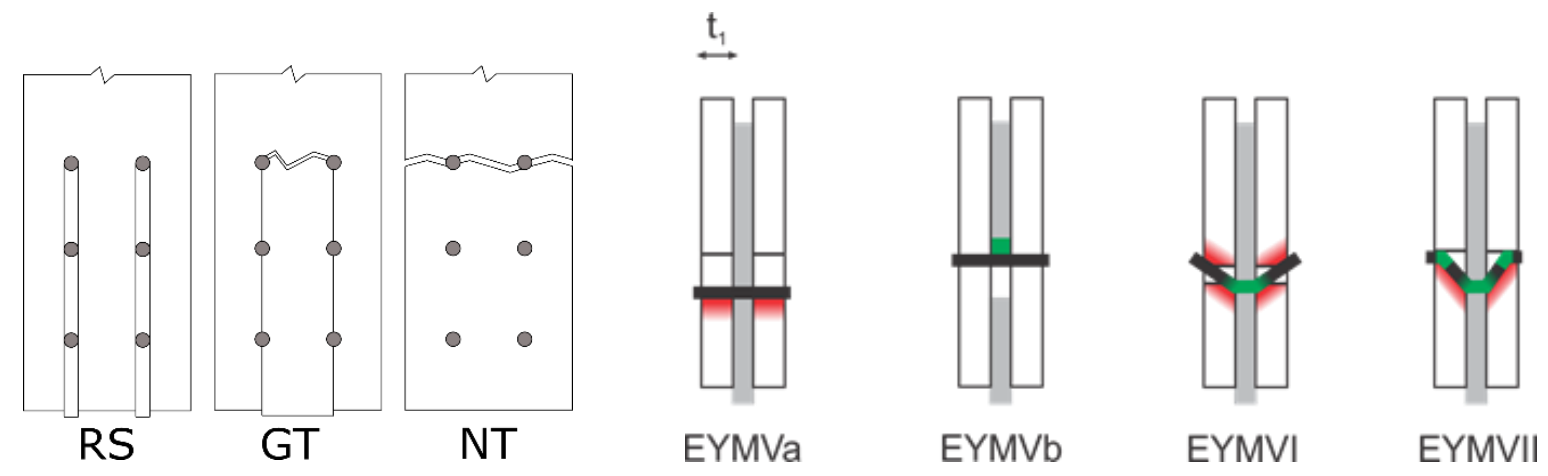

(a)

(b)

323 Fig. 2. (a) Brittle failure modes (Row Shear, Group tear-out, Net tensile failure) (b) Ductile

324 modes according to European Yield Model (red shows timber crushing, green shows steel

325 yielding)

326 


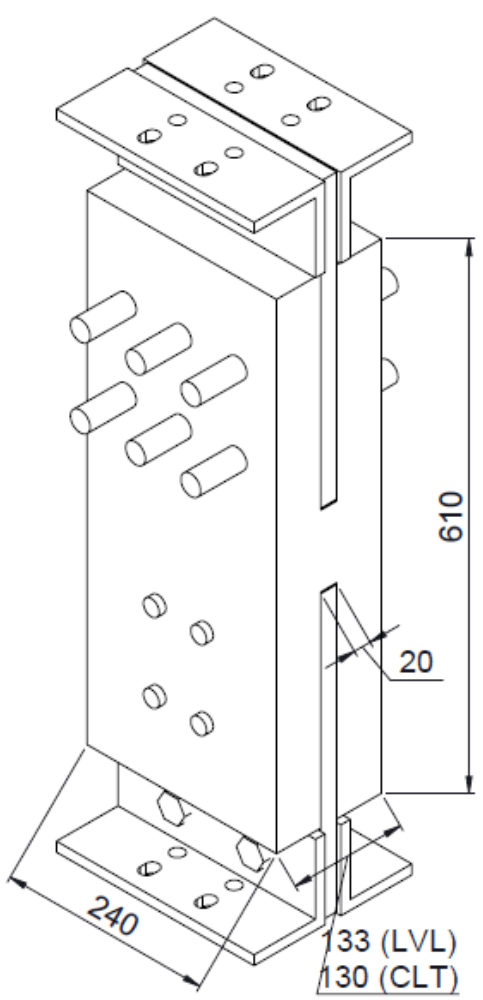

(a)

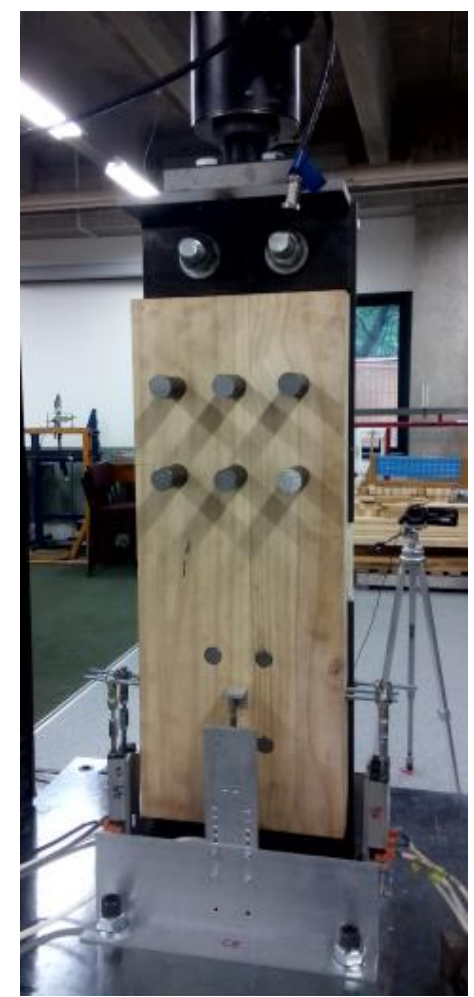

(b)

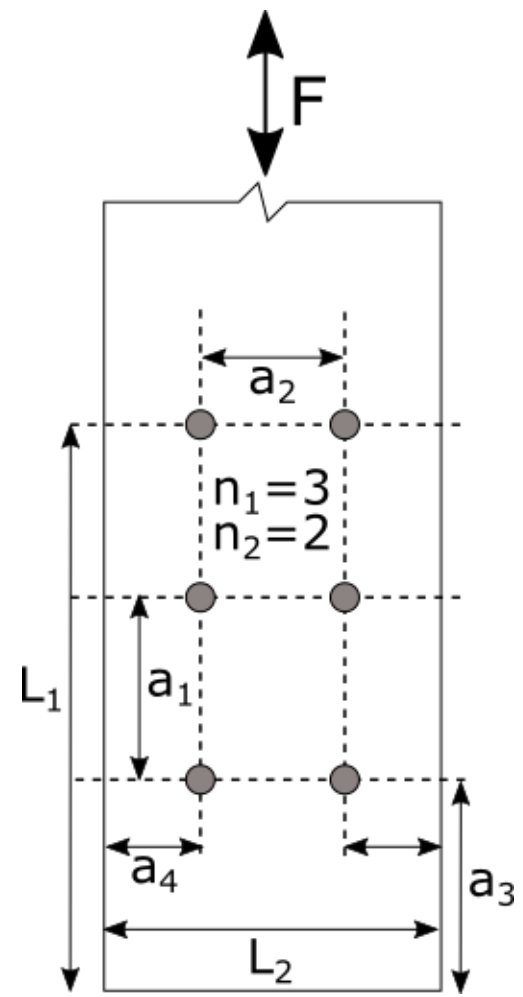

(c)

327 Fig. 3. (a) Layout and (b) set-up for monotonic and cyclic testing (c) fastener spacing 328 


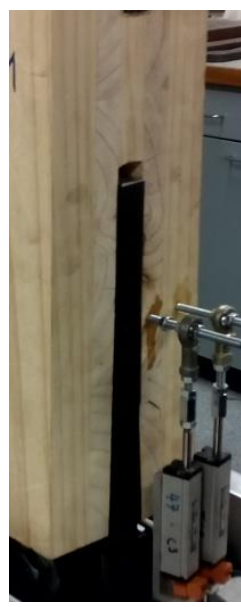

(a)

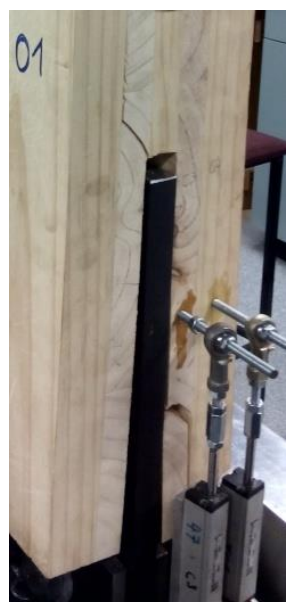

(b)

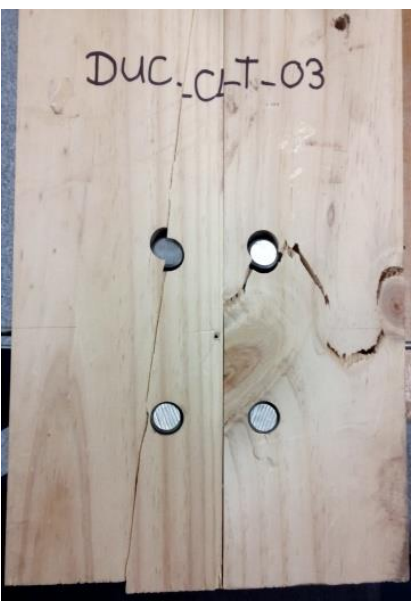

(c)

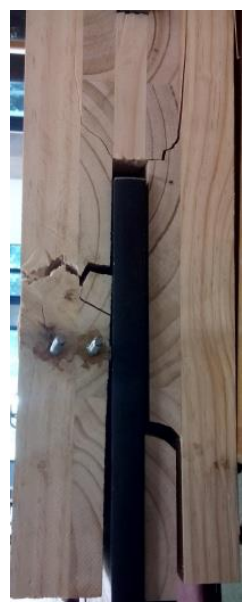

(d)

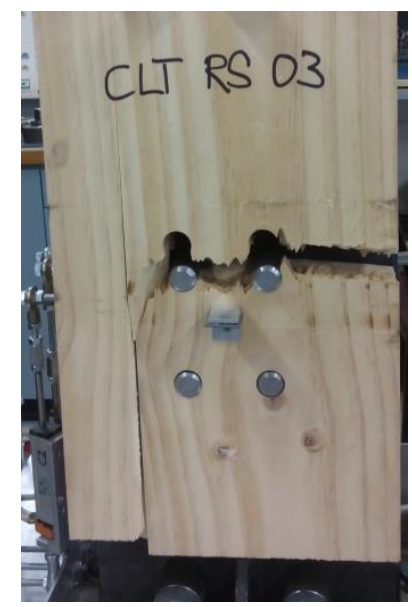

(e)

329 Fig. 4. Failure in CLT specimens from left to right: (a) onset of cracking in cross layer, (b) crack 330 propagation, (c) DT layout failure front, (d) DT layout failure side, (e) RS layout failure 


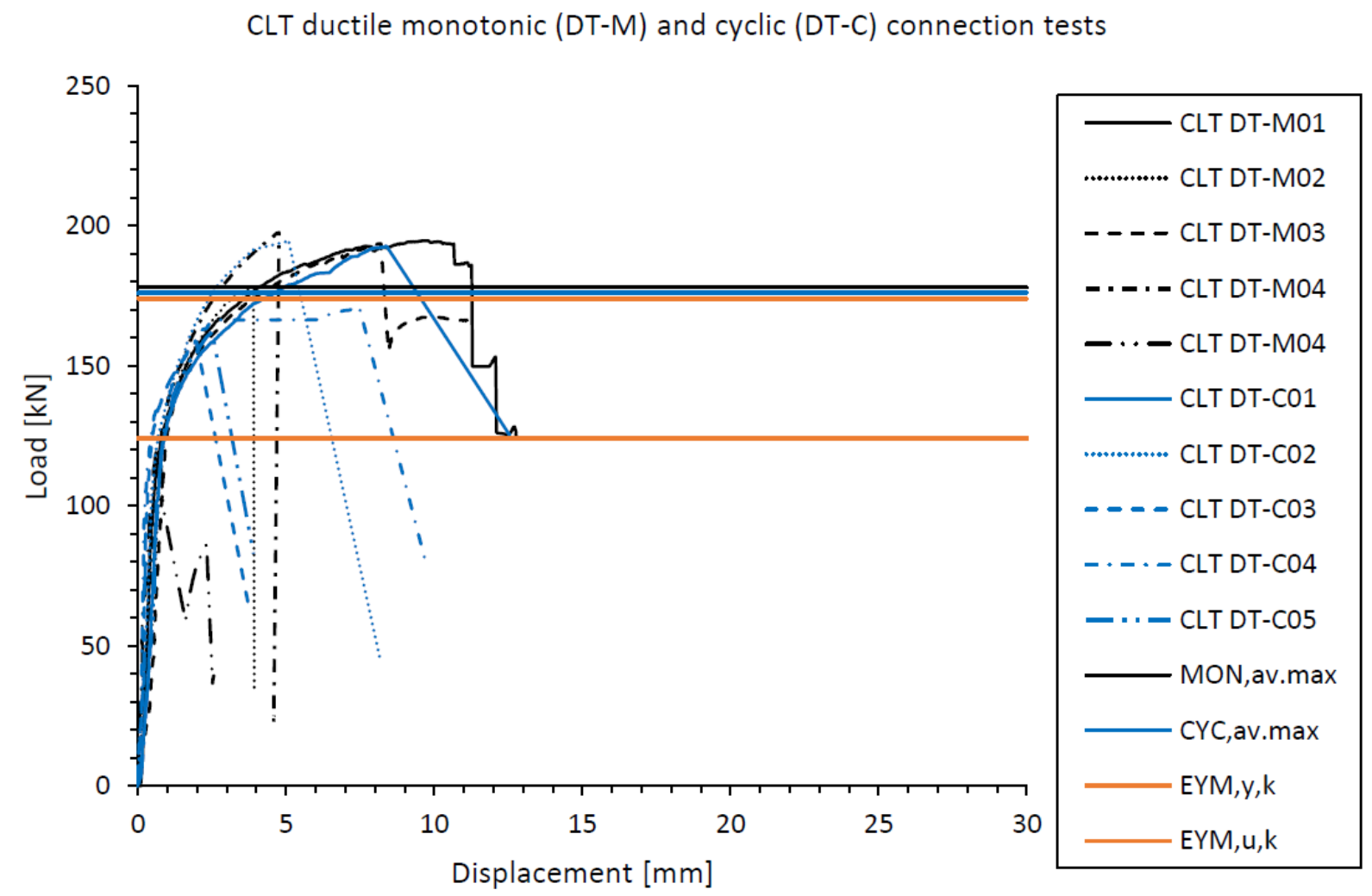

333 Fig. 5. Load displacement curves of CLT connections with ductile layout 


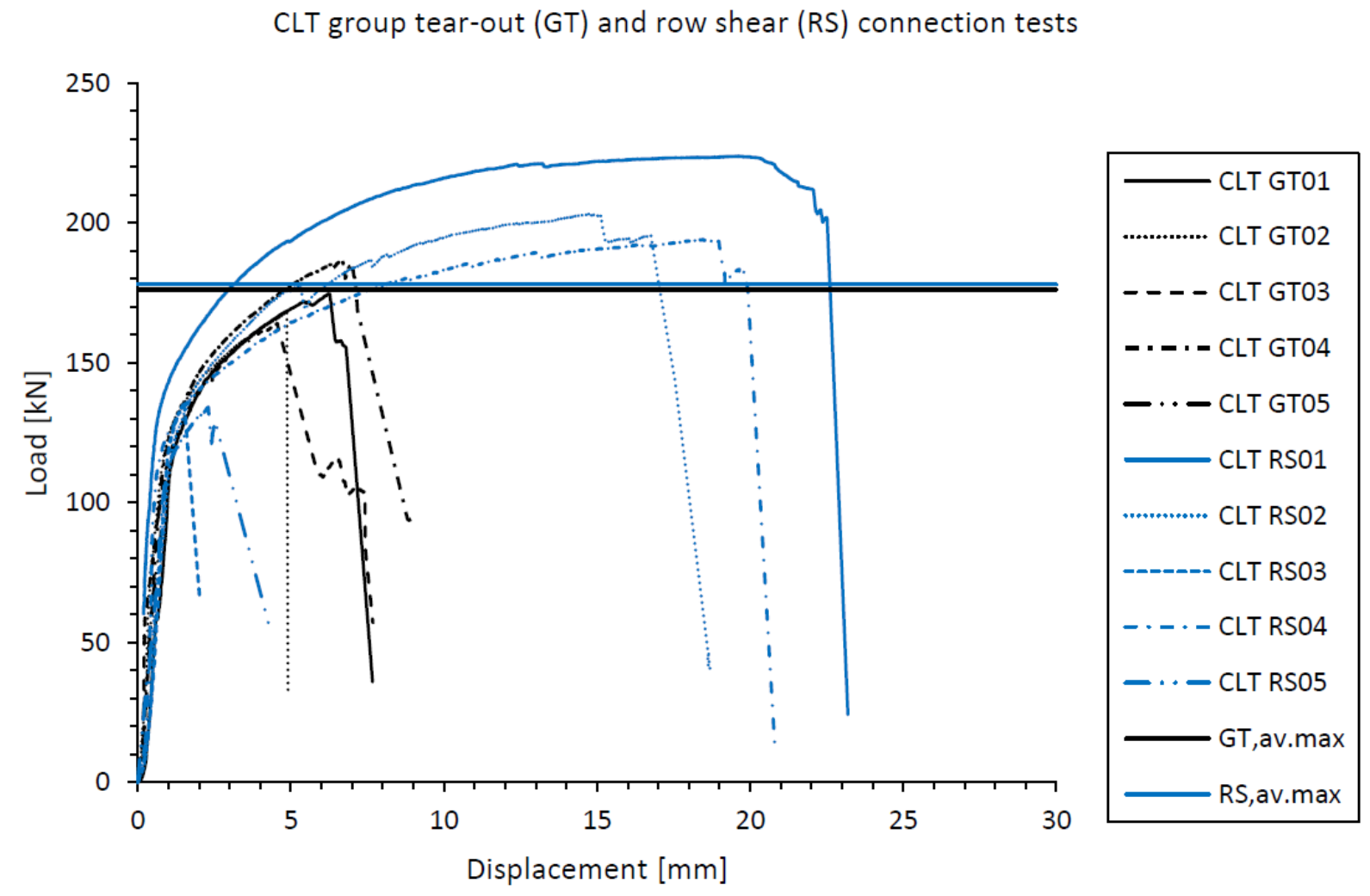

336 Fig. 6. Load displacement curves of CLT connections with brittle layout 


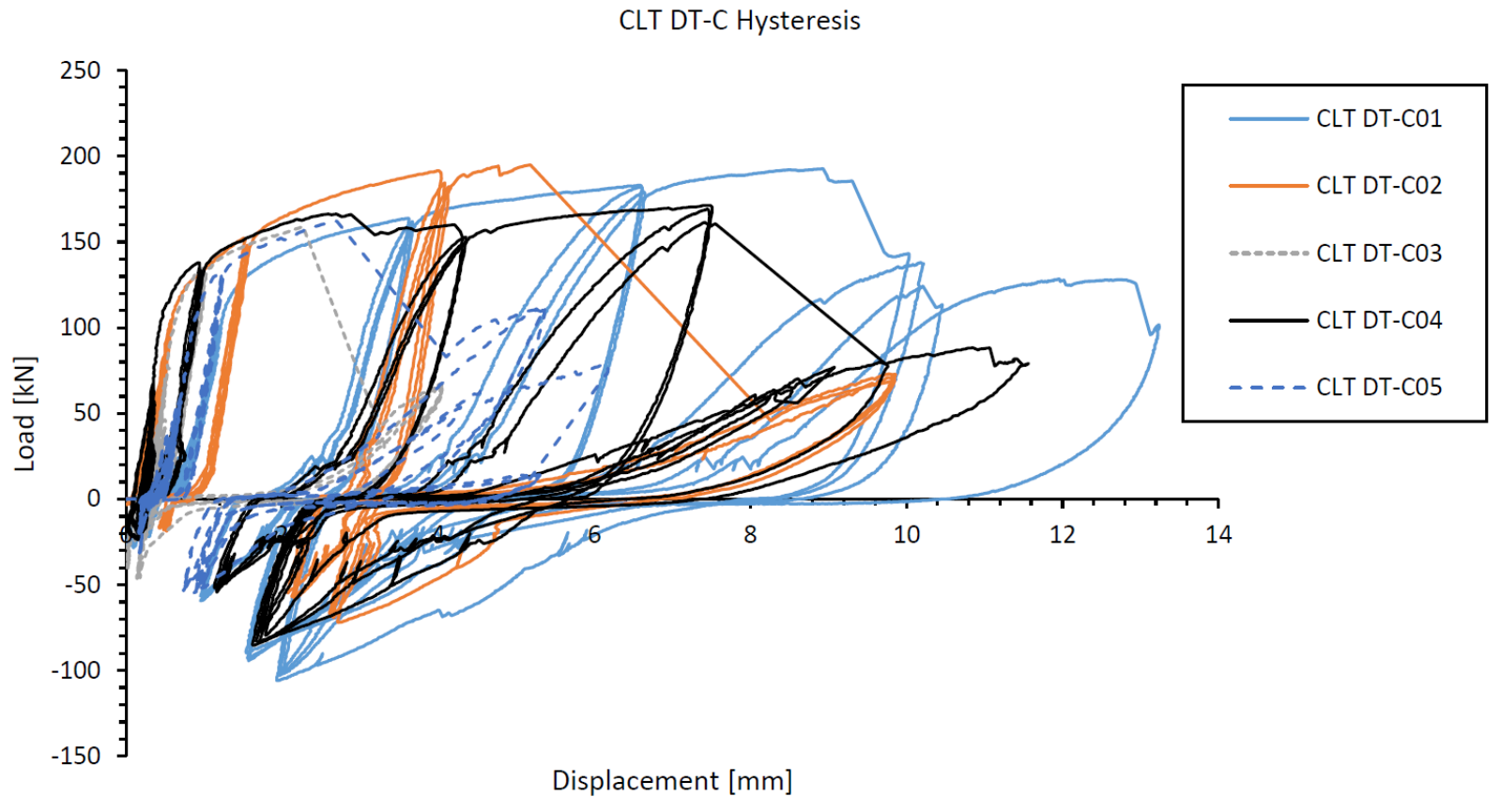

338

339 Fig. 7. Hysteresis curves of CLT connections

340 


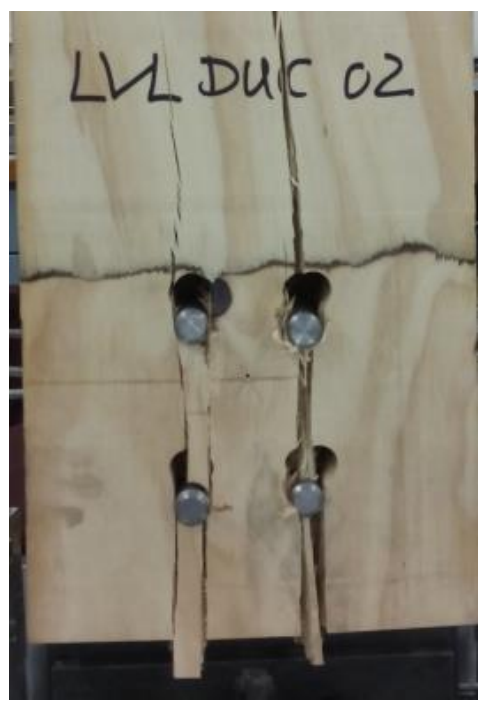

(a)

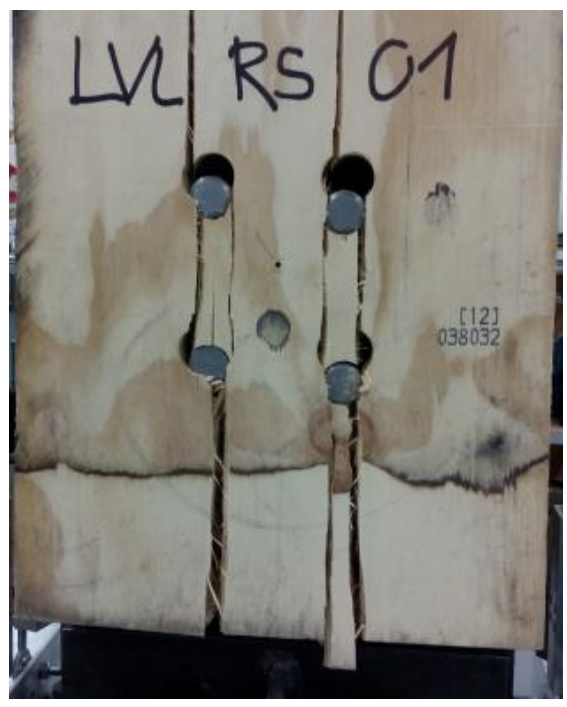

(b)

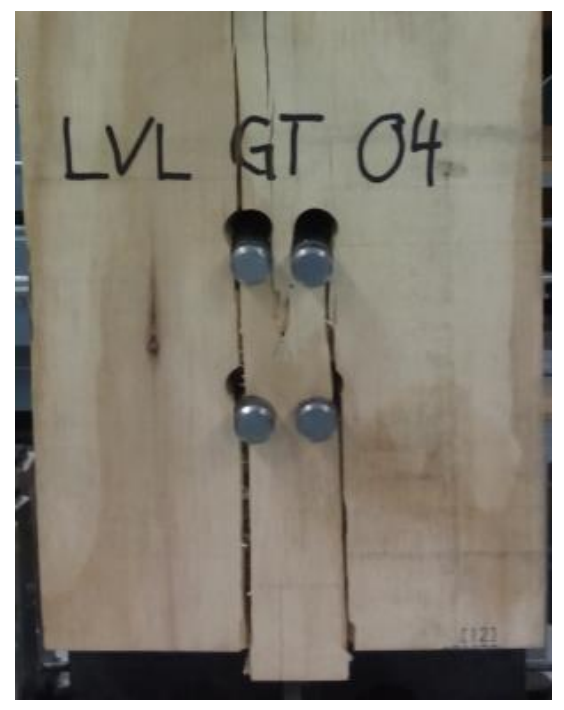

(c)

342 Fig. 8. LVL failure: (a) Row shear in DT-C and (b) RS layout, (c) group tear-out in GT layout 343 
LVL ductile monotonic (DT-M) and cyclic (DT-C) connection tests

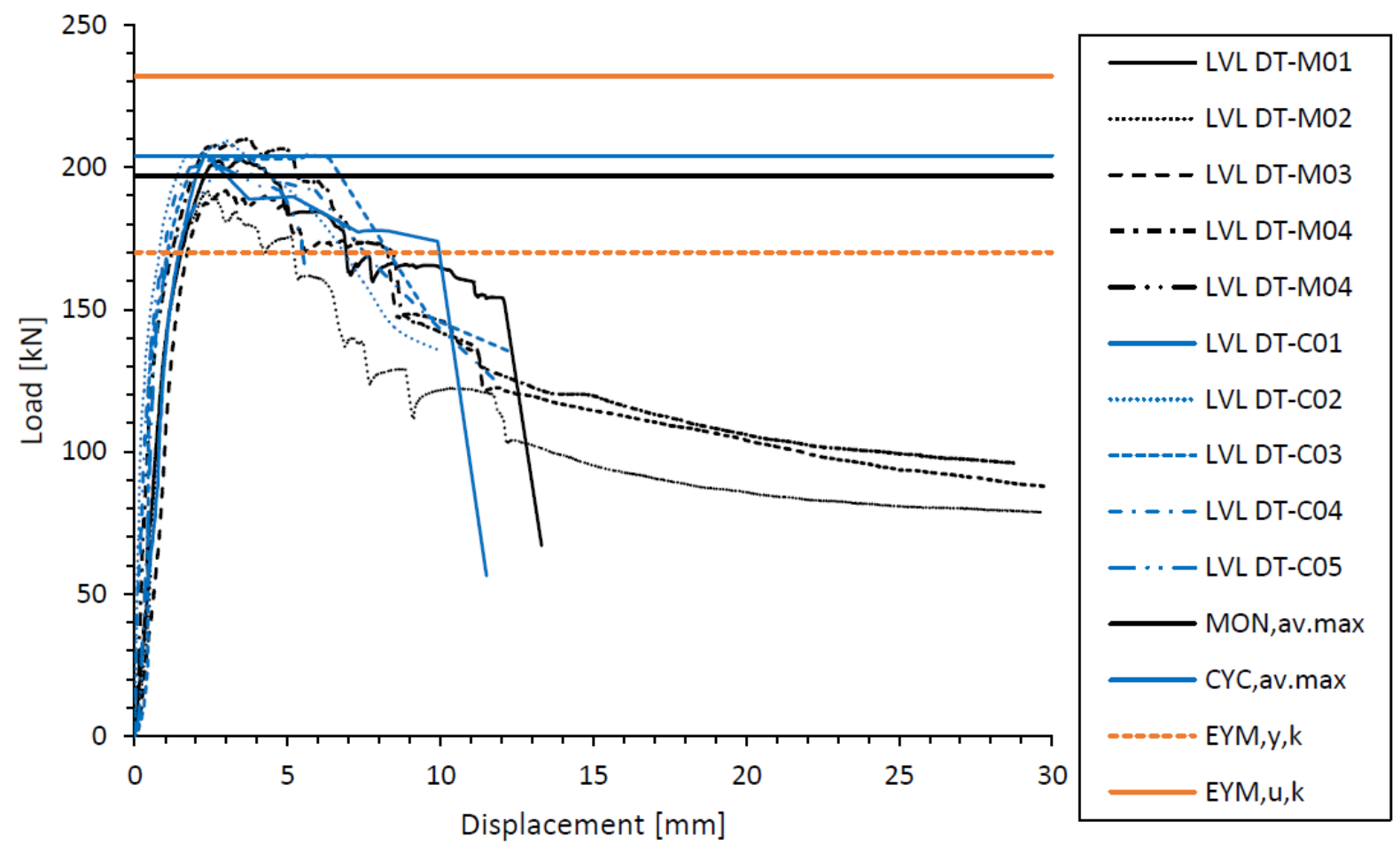

345 Fig. 9. Load displacement curves of LVL connections with ductile layout 
LVL group tear-out (GT) and row shear (RS) connection tests

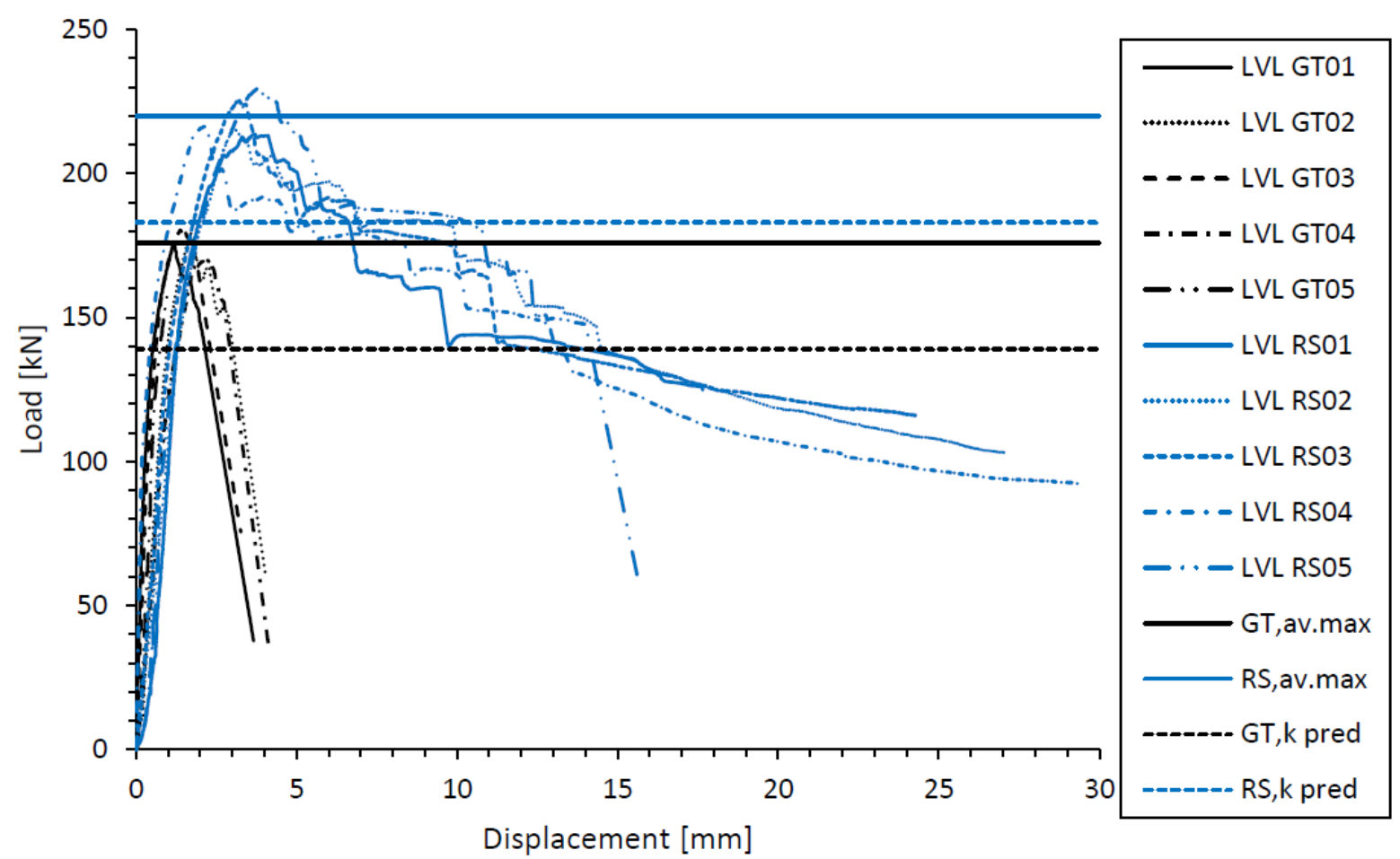

348 Fig. 10. Load displacement curves of LVL connections with brittle layout 


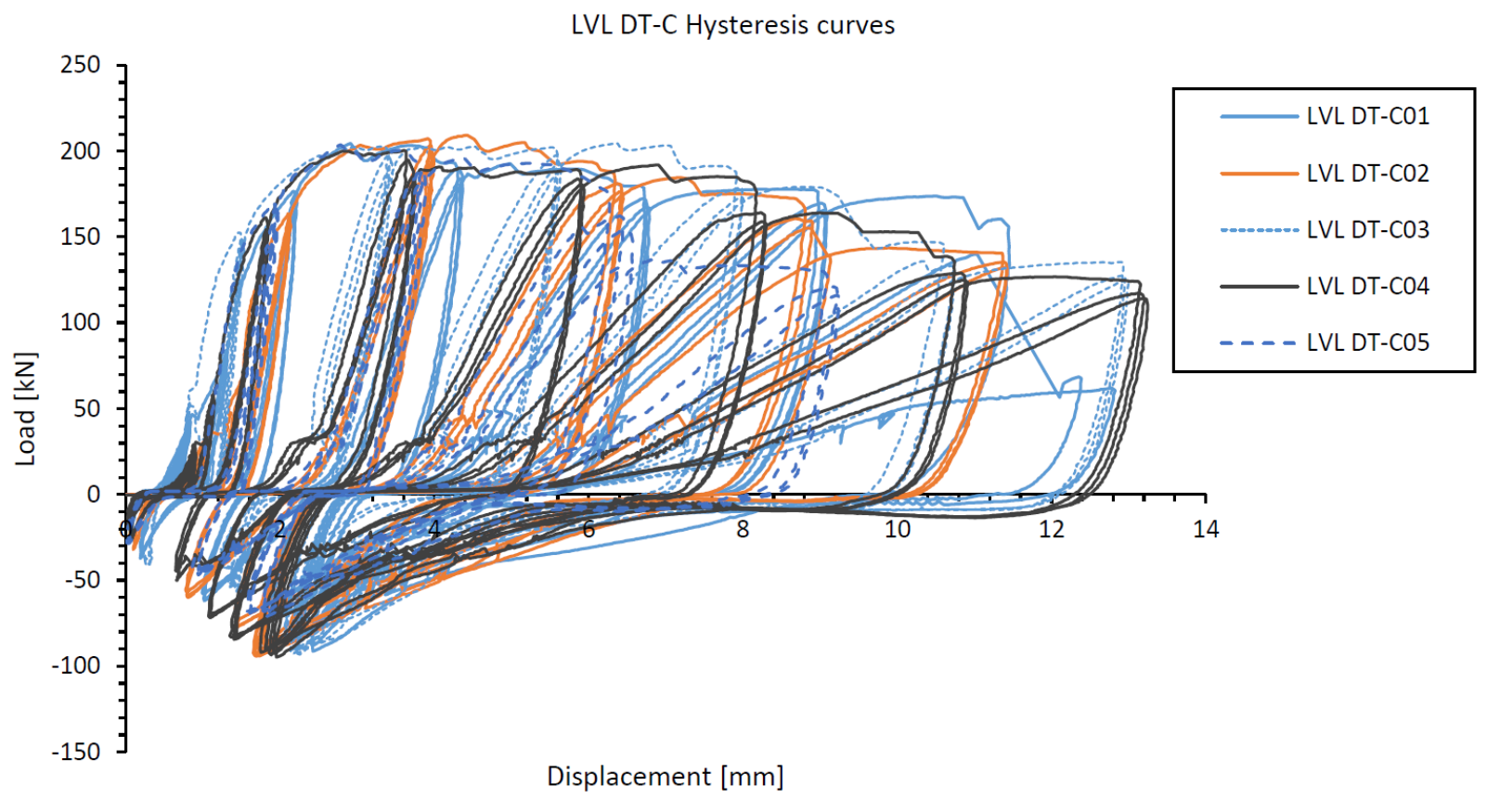

350

351 Fig. 11. Hysteresis curves of LVL connections

352 


\section{TABLES}

354 Table 1. Specimen layout

$$
\text { Experimental layout Design recommendations }
$$

$\begin{array}{llll}\text { Ductile layout } & \text { Brittle layouts } & \text { LVL } & \text { CLT }\end{array}$

DT-M / DT-C RS GT-CLT GT-LVL Eurocode 5 Handbook

\begin{tabular}{lllllll}
\hline$a_{1}[\mathrm{~mm}]$ & $100 / 5 d$ & $80 / 4 d$ & $80 / 4 d$ & $80 / 4 d$ & $5 d$ & $4 d$ \\
$a_{2}[\mathrm{~mm}]$ & $60 / 3 d$ & $60 / 3 d$ & $40 / 2 d$ & $30 / 1.5 d$ & $3 d$ & $4 d$ \\
$a_{3}[\mathrm{~mm}]$ & $100 / 5 d$ & $140 / 7 d$ & $140 / 7 d$ & $140 / 7 d$ & $7 d$ & $5 d$ \\
$a_{4}[\mathrm{~mm}]$ & $90 / 4.5 d$ & $90 / 4.5 d$ & $100 / 5 d$ & $105 / 5.25 d$ & $3 d$ & $3 d$
\end{tabular}


358 Table 2. Characteristic strength properties for connection strength predictions

\begin{tabular}{rrrrrrr}
\hline & $f_{v, k}[\mathrm{MPa}]$ & $f_{t, k}[\mathrm{MPa}]$ & $f_{h, y, k}[\mathrm{MPa}]$ & $f_{h, u, k}[\mathrm{MPa}]$ & $M_{y, p}[\mathrm{Nmm}]$ & $M_{y, e}[\mathrm{Nmm}]$ \\
\hline LVL & 5.30 & 33.00 & 32.50 & 40.63 & 428,700 & 252,525 \\
CLT & 3.80 & 8.80 & 20.85 & 26.06 & 428,700 & 252,525
\end{tabular}

359

360 
362 Table 3. Strength predictions of connections with different layouts (DT-M: ductile monotonic, 363 DT-C: ductile cyclic, RS: row shear layout, GT: group tear-out layout, NA: not available, 364 governing mode printed in bold)

\begin{tabular}{|c|c|c|c|c|c|c|}
\hline \multirow{2}{*}{$\begin{array}{l}\text { Force } \\
{[\mathrm{kN}]}\end{array}$} & \multicolumn{3}{|c|}{ CLT } & \multicolumn{3}{|c|}{ LVL } \\
\hline & DT-M / DT-C & RS & GT & DT-M / DT-C & RS & GT \\
\hline$\overline{F_{E Y M y, k}}$ & 124 & 124 & 124 & 170 & 170 & 170 \\
\hline$F_{E Y M u, k}$ & 174 & 174 & 174 & 232 & 232 & 232 \\
\hline$F_{R S u, k}$ & NA & NA & NA & 235 & 183 & 183 \\
\hline$F_{G T u, k}$ & NA & NA & NA & 306 & 280 & 139 \\
\hline
\end{tabular}


367 Table 4. CLT DT layout test results (av. = average)

\begin{tabular}{lrrrrrrrrrrrr}
\hline CLT & \multicolumn{1}{c}{ DT-M (ductile monotonic) } & \multicolumn{1}{c}{ DT-C (ductile cyclic) } \\
\hline test number & 1 & 2 & 3 & 4 & 5 & av. & 1 & 2 & 3 & 4 & 5 & av. \\
& & & & & & & & & & & & \\
\hline$F_{y}[\mathrm{kN}]$ & 117 & 142 & 135 & 137 & 124 & 131 & 121 & 125 & 120 & 124 & 134 & 125 \\
$F_{\max }[\mathrm{kN}]$ & 195 & 178 & 194 & 198 & 124 & 178 & 193 & 195 & 159 & 171 & 162 & 176 \\
$F_{u}[\mathrm{kN}]$ & 156 & 178 & 155 & 198 & 99 & 157 & 154 & 156 & 127 & 137 & 130 & 141 \\
$\Delta_{y}[\mathrm{~mm}]$ & 0.6 & 1.2 & 1.1 & 0.9 & 0.7 & 0.9 & 0.9 & 0.6 & 0.5 & 0.9 & 1.0 & 0.8 \\
$\Delta_{F \max }[\mathrm{mm}]$ & 9.5 & 3.7 & 8.2 & 4.8 & 0.7 & 5.4 & 8.5 & 5.1 & 2.0 & 7.5 & 2.4 & 5.1 \\
$\Delta_{u}[\mathrm{~mm}]$ & 10.9 & 3.7 & 8.5 & 4.8 & 0.8 & 5.7 & 9.2 & 5.9 & 2.4 & 7.9 & 3.0 & 5.7 \\
$K[\mathrm{kN} / \mathrm{mm}]$ & 202 & 121 & 125 & 157 & 177 & 157 & 138 & 211 & 241 & 134 & 176 & 180 \\
$\operatorname{mode}$ & $\mathrm{D}$ & $\mathrm{B}$ & $\mathrm{D}$ & $\mathrm{M}$ & $\mathrm{B}$ & $\mathrm{M}$ & $\mathrm{D}$ & $\mathrm{D}$ & $\mathrm{M}$ & $\mathrm{D}$ & $\mathrm{M}$ & $\mathrm{D}$ \\
$\mu=\Delta_{u} / \Delta_{y}$ & 18.8 & 3.2 & 7.8 & 5.5 & 1.1 & 7.3 & 10.5 & 10.0 & 4.7 & 8.6 & 8.2 & 8.4
\end{tabular}


370 Table 5. CLT GT and RS layout test results (av. = average)

\begin{tabular}{lrrrrrrrrrrrrr}
\hline CLT & \multicolumn{10}{c}{ GT (group tear-out) } & & \multicolumn{5}{c}{ RS (row shear) } \\
\hline test number & 1 & 2 & 3 & 4 & 5 & av. & 1 & 2 & 3 & 4 & 5 & av. \\
& & & & & & & & & & & & \\
\hline$F_{y}[\mathrm{kN}]$ & 123 & 106 & 106 & 119 & 130 & 117 & 125 & 117 & 129 & 120 & 122 & 123 \\
$F_{\max }[\mathrm{kN}]$ & 175 & 168 & 164 & 187 & 186 & 176 & 224 & 203 & 136 & 194 & 134 & 178 \\
$F_{u}[\mathrm{kN}]$ & 140 & 168 & 131 & 149 & 149 & 147 & 179 & 163 & 109 & 155 & 107 & 143 \\
$\Delta_{y}[\mathrm{~mm}]$ & 1.2 & 0.5 & 0.6 & 0.8 & 1.2 & 0.9 & 0.9 & 1.0 & 1.2 & 0.8 & 0.9 & 0.9 \\
$\Delta_{F m a x}[\mathrm{~mm}]$ & 6.3 & 4.9 & 4.6 & 6.7 & 7.7 & 6.0 & 19.5 & 14.7 & 1.5 & 18.6 & 2.3 & 11.3 \\
$\Delta_{u}[\mathrm{~mm}]$ & 6.9 & 4.9 & 5.4 & 7.6 & 14.9 & 7.9 & 22.6 & 17.3 & 1.7 & 19.7 & 3.0 & 12.9 \\
$K[\mathrm{kN} / \mathrm{mm}]$ & 103 & 197 & 186 & 145 & 111 & 148 & 136 & 120 & 108 & 158 & 139 & 132 \\
$\operatorname{mode}$ & $\mathrm{M}$ & $\mathrm{D}$ & $\mathrm{D}$ & $\mathrm{D}$ & $\mathrm{D}$ & $\mathrm{D}$ & $\mathrm{D}$ & $\mathrm{D}$ & $\mathrm{B}$ & $\mathrm{D}$ & $\mathrm{B}$ & $\mathrm{D}$ \\
$\mu=\Delta_{u} / \Delta_{y}$ & 5.8 & 9.0 & 9.4 & 9.3 & 12.6 & 9.2 & 24.6 & 17.7 & 1.4 & 25.9 & 3.4 & 14.6
\end{tabular}


373 Table 6. LVL DT layout test results (av. = average)

\begin{tabular}{lcclllllllllll}
\hline LVL & \multicolumn{1}{c}{ DT-M (ductile monotonic) } & \multicolumn{1}{c}{ DT-C (ductile cyclic) } \\
\hline test number & 1 & 2 & 3 & 4 & 5 & av. & 1 & 2 & 3 & 4 & 5 & av. \\
\hline$F_{y}[\mathrm{kN}]$ & 184 & 163 & 184 & 159 & 178 & 173 & 163 & 167 & 130 & 178 & 158 & 159 \\
$F_{\max }[\mathrm{kN}]$ & 203 & 192 & 192 & 210 & 190 & 197 & 205 & 209 & 204 & 200 & 201 & 204 \\
$F_{u}[\mathrm{kN}]$ & 162 & 153 & 153 & 168 & 152 & 158 & 164 & 167 & 164 & 160 & 161 & 163 \\
$\Delta_{y}[\mathrm{~mm}]$ & 1.3 & 1.1 & 1.7 & 0.9 & 1.3 & 1.2 & 1.2 & 0.9 & 0.6 & 0.9 & 0.8 & 0.8 \\
$\Delta_{F m a x}[\mathrm{~mm}]$ & 3.5 & 2.4 & 3.0 & 3.8 & 2.2 & 3.0 & 2.1 & 3.0 & 5.7 & 2.6 & 2.0 & 3.1 \\
$\Delta_{u}[\mathrm{~mm}]$ & 7.0 & 6.5 & 8.5 & 8.5 & 6.3 & 7.4 & 10.5 & 7.4 & 8.7 & 7.3 & 5.5 & 7.9 \\
$K[\mathrm{kN} / \mathrm{mm}]$ & 142 & 148 & 108 & 186 & 137 & 144 & 141 & 196 & 232 & 198 & 211 & 196 \\
$\operatorname{mode}$ & $\mathrm{M}$ & $\mathrm{M}$ & $\mathrm{M}$ & $\mathrm{D}$ & $\mathrm{M}$ & $\mathrm{M}$ & $\mathrm{D}$ & $\mathrm{D}$ & $\mathrm{D}$ & $\mathrm{D}$ & $\mathrm{D}$ & $\mathrm{D}$ \\
$\mu=\Delta_{u} / \Delta_{y}$ & 5.5 & 5.9 & 5.0 & 10.0 & 4.9 & 6.2 & 9.1 & 8.7 & 15.5 & 8.1 & 7.3 & 9.8 \\
\hline
\end{tabular}


376 Table 7. LVL GT and RS layout test results (av. = average)

\begin{tabular}{|c|c|c|c|c|c|c|c|c|c|c|c|c|}
\hline LVL & \multicolumn{9}{|c|}{ GT (group tear-out) } & \multicolumn{3}{|c|}{ RS (row shear) } \\
\hline test number & 1 & 2 & 3 & 4 & 5 & av. & 1 & 2 & 3 & 4 & 5 & av. \\
\hline$F_{y}[\mathrm{kN}]$ & 176 & 151 & 174 & 154 & 155 & 162 & 181 & 196 & 186 & 145 & 155 & 160 \\
\hline$F_{\max }[\mathrm{kN}]$ & 176 & 180 & 181 & 170 & 172 & 176 & 214 & 215 & 225 & 216 & 229 & 220 \\
\hline$F_{u}[\mathrm{kN}]$ & 141 & 144 & 145 & 136 & 138 & 140 & 171 & 172 & 180 & 173 & 184 & 176 \\
\hline$\Delta_{y}[\mathrm{~mm}]$ & 1.2 & 0.9 & 1.6 & 1.2 & 0.8 & 1.1 & 1.6 & 1.9 & 1.4 & 0.6 & 0.8 & 1.1 \\
\hline$\Delta_{\text {Fmax }}[\mathrm{mm}]$ & 1.2 & 1.7 & 2.0 & 2.2 & 1.7 & 1.8 & 3.7 & 3.0 & 3.2 & 2.1 & 3.5 & 3.8 \\
\hline$\Delta_{u}[\mathrm{~mm}]$ & 2.1 & 3.0 & 2.8 & 3.1 & 2.4 & 2.7 & 6.9 & 10.0 & 7.0 & 7.5 & 9.9 & 8.3 \\
\hline$K[\mathrm{kN} / \mathrm{mm}]$ & 147 & 168 & 109 & 128 & 194 & 149 & 112 & 104 & 136 & 242 & 194 & 157 \\
\hline mode & B & B & B & B & B & B & M & $\mathrm{M}$ & M & D & D & M \\
\hline$\mu=\Delta_{u} / \Delta_{y}$ & 1.8 & 3.3 & 1.7 & 2.5 & 3.0 & 2.5 & 4.3 & 5.3 & 5.1 & 12.5 & 12.4 & 7.9 \\
\hline
\end{tabular}


379 Table 8. Average ductility and ultimate displacement of connection tests

\begin{tabular}{ccccccccc}
\hline & \multicolumn{3}{c}{ CLT } & \multicolumn{5}{c}{ LVL } \\
\hline & DT-M & DT-C & GT & RS & DT-M & DT-C & GT & RS \\
\hline$\mu_{a v}[-]$ & 7.3 & 8.4 & 9.2 & 14.6 & 6.2 & 9.8 & 2.5 & 7.9 \\
$\Delta_{u, a v}[\mathrm{~mm}]$ & 5.7 & 5.7 & 7.9 & 12.9 & 7.4 & 7.9 & 2.7 & 8.3 \\
average & & & & & & & & \\
mode & $\mathrm{M}$ & $\mathrm{D}$ & $\mathrm{D}$ & $\mathrm{D}$ & $\mathrm{M}$ & $\mathrm{D}$ & $\mathrm{B}$ & $\mathrm{M}$ \\
& & & & & & & & \\
\hline
\end{tabular}


382 Table 9. Comparison of strength prediction with experimental results

\begin{tabular}{llrrrr}
\hline & & \multicolumn{2}{c}{ CLT } & & \\
\hline & & average & predicted & average & predicted \\
& & maximum & characteristic & maximum & characteristic \\
& & 131 & 124 & 173 & 170 \\
DT-M & $F_{y}[\mathrm{kN}]$ & 178 & 174 & 197 & 216 \\
& $F_{\max }[\mathrm{kN}]$ & 125 & 124 & 159 & 170 \\
DT-C & $F_{y}[\mathrm{kN}]$ & 176 & 174 & 204 & 216 \\
& $F_{\max }[\mathrm{kN}]$ & 117 & 124 & 162 & 170 \\
GT & $F_{y}[\mathrm{kN}]$ & 176 & - & 176 & 139 \\
& $F_{\max }[\mathrm{kN}]$ & 123 & 124 & 172 & 170 \\
RS & $F_{y}[\mathrm{kN}]$ & 178 & - & 220 & 183 \\
& $F_{\max }[\mathrm{kN}]$ & & & &
\end{tabular}

383

384 


\section{NOTATIONS}

\begin{tabular}{|c|c|}
\hline$C Y C_{a v \cdot \max }$ & cyclic average maximum strength \\
\hline$D T$ & ductile layout designation or strength \\
\hline$F_{B R r e d}$ & reduced brittle connection strength \\
\hline$F_{B R u}$ & ultimate brittle connection strength \\
\hline$F_{d}$ & design strength \\
\hline$F_{E Y M u}$ & ultimate ductile connection strength based on European Yield Model \\
\hline$F_{E Y M y}$ & connection's yield strength based on European Yield Model \\
\hline$F_{G T}$ & group tear-out strength \\
\hline$F_{k}$ & characteristic strength \\
\hline$F_{\max }$ & connection's peak strength \\
\hline$F_{R S}$ & row shear strength \\
\hline$F_{u}$ & connection's ultimate strength \\
\hline$F_{y}$ & connection's yield strength / yield point \\
\hline$G T_{a v . \max }$ & group tear-out layout average maximum strength \\
\hline$K$ & initial stiffness \\
\hline$k_{L S}$ & loading surface factor ( 0.65 for internal steel plate) \\
\hline$M_{y, e}$ & fastener's elastic yield moment \\
\hline$M_{y, p}$ & fastener's plastic yield moment \\
\hline$M O N_{a v . m a x}$ & monotonic average maximum strength \\
\hline$R S_{a v . \max }$ & row shear layout average maximum strength \\
\hline
\end{tabular}




$\begin{array}{ll}a_{1} & \text { fastener spacing in row } \\ a_{2} & \text { fastener spacing between rows } \\ a_{3} & \text { edge distance in to loaded edge } \\ a_{4} & \text { edge distance to unloaded edge } \\ d & \text { fastener diameter } \\ f_{h, u} & \text { ultimate embedment strength } \\ f_{h, y} & \text { yield embedment strength } \\ f_{t} & \text { tensile strength } \\ f_{u} & \text { fastener ultimate tensile strength } \\ f_{v} & \text { shear strength } \\ f_{y} & \text { fastener yield strength } \\ t_{1} & \text { single side timber member thickness }\end{array}$

$\alpha_{1}$

$\alpha_{2}$

$\Delta_{\text {Fmax }}$

$\Delta_{u}$

$\Delta_{y} \quad$ yield displacement

$\mu \quad$ ductility

$\rho \quad$ timber density 
- American Society for Testing and Materials, ASTM D5764-97a (2013). "Standard Test Method for Evaluating Dowel-Bearing Strength of Wood and Wood-Based Products. Standard test method for evaluating dowel- bearing strength of wood and wood-base products". ASTM International, West Conshohocken, PA.

- Australian/New Zealand Standard, AS/NZS 4357.0:2005 (2005). "Structural Laminated Veneer Lumber." Standards Australia, GPO Box 476, Sydney, NSW 2001 and Standards New Zealand, Wellington 6140.

- Australian/New Zealand Standard, AS/NZS 4671:2001 (2001). "Steel reinforcing materials (2001)." Standards Australia, GPO Box 476, Sydney, NSW 2001 and Standards New Zealand, Private Bag 2439, Wellington 6140.

- Australian/New Zealand Standard, AS/NZS ISO 10984.1:2015 (2015). “Timber structures - Dowel-type fasteners - Determination of yield moment" (2015). Standards Australia, GPO Box 476, Sydney, NSW 2001 and Standards New Zealand, Private Bag 2439, Wellington 6140.

- Australian/New Zealand Standard, AS/NZS ISO 10984.2:2015 (2015). “Timber structures - Dowel-type fasteners - Determination of embedding strength" (2015). Standards Australia, GPO Box 476, Sydney, NSW 2001 and Standards New Zealand, Private Bag 2439, Wellington 6140 .

- Brühl, F., Kuhlmann, U., Jorissen, A. (2011). “Consideration of plasticity within the design of timber structures due to connection ductility." Engineering Structures, 33(11), 30073017. 
- European Standard EN 1995-1-1 2004/A1 2008 Eurocode 5 (2004/2008). "Design of

413 timber structures - part 1-1: general- common rules and rules for buildings/incl Amendment

414 A1.” European Committee for Standardization, Bruxelles (Belgium).

415 - European Standard EN 12512 (2013): “Timber structures - Test methods - Cyclic testing 416 of joints made with mechanical fasteners." European Committee for Standardization 417 (CEN), Bruxelles. (2013)

418 - Flatscher, G. (2016). "Evaluation and approximation of timber connection properties for 419 displacement-based simulation of CLT wall systems (working title)", Doctoral thesis, Graz $420 \quad$ University of Technology, Austria

421 - Franke, S., Quenneville, P. (2011). "Bolted and dowelled connections in radiate pine and 422 laminated veneer lumber using the European yield model." Australian Journal of $423 \quad$ Structural Engineering, 12(1), 13-28.

424 - International Organization for Standardization ISO 16670:2003 (2003). “Timber structures 425 - Joints made with mechanical fasteners - Quasi-static reversed-cyclic test method 426 (2003).” The international Organization for Standardization, Genava.

427 - Jensen, J. L., \& Quenneville, P. (2011). Experimental investigations on row shear and 428 splitting in bolted connections. Construction and Building Materials, 25(5), 2420-2425.

429 - Jorissen, A., Fragiacomo, M. (2011). "General notes on ductility in timber structures." $430 \quad$ Engineering Structures, 33(11), 2987-2997.

431 - Karacabeyli, E., Desjardins, R. Eds (2011). “CLT Handbook.” FPInnovations.

432 - Mohammad, M., Quenneville, J. H. P., Smith, I. (1998). "Influence of cyclic loads on 433 strength and stiffness of bolted timber connections." Proceedings of the 5th World 434 Conference on Timber Engineering Vol. 1, pp. 375-382. 
- Moroder, D., Smith, T., Pampanin, S., Palermo, A., Buchanan, A. H. (2014). "Design of Floor Diaphragms in Multi-Storey Timber Buildings.” Proc. INTER, 2014.

- Novis, S. A. L., Jacks, J., \& Quenneville, P. (2016). "Predicting the Resistance and Displacement of Timber Bolted Connections.” In Proceedings WCTE, 2016.

- Ottenhaus, L.M., Li, M., Smith, T., \& Quenneville, P. (2016). "Ductility and Overstrength of Dowelled LVL and CLT Connections Under Cyclic Loading.” In Proceedings WCTE, 2016.

- Ottenhaus, L.-M., Li, M., Smith, T., \& Quenneville, P. (2017). Overstrength of dowelled CLT connections under monotonic and cyclic loading. Bulletin of Earthquake Engineering.

- Piazza, M., Polastri, A., Tomasi, R. (2011). "Ductility of timber joints under static and cyclic loads." Proceedings of the ICE - Structures and Buildings, 164(2), 79-90. 206.

- Quenneville, P., \& Morris, H. (2009). "Proposal for a mechanics-based bolted connection

- Smith, T., Moroder, D., Sarti, F., Pampanin, S., Buchanan, A.H. (2015). "The Reality of Seismic Engineering in a Modern Timber World.” Proc. INTER, 2015.

- Smith, I., Asiz, A., Snow, M., Chui, Y. H. (2006). "Possible Canadian / ISO Approach to Deriving Design Values from Test Data." CIB W18 Meeting Thirty-Nine, Florence, (August).

- Yasumura, M. "Mechanical properties of dowel type joints under reversed cyclic lateral loading." Proceedings CIB-W18-meeting. Savonlinna, Finland. Universität Karlsruhe, CIB W. Vol. 18. 1998. 
